\title{
Medial Forebrain Bundle
}

National Cancer Institute

\section{Source}

National Cancer Institute. Medial Forebrain Bundle. NCI Thesaurus. Code C13083.

A complex tract of nerve fibers that connects the basal telencephalon, the hypothalamus, and the midbrain reticular formation. The medial forebrain bundle contains fibers involved in the reward pathway of the brain. 